\title{
Cloning of Aminoglycoside-resistance Determinants from Streptomyces tenebrarius and Comparison with Related Genes from Other Actinomycetes
}

\author{
By PATRICIA A. SKEGGS, DAVID J. HOLMES AND ERIC CUNDLIFFE* \\ Department of Biochemistry, University of Leicester, Adrian Building, University Road, \\ Leicester LE1 7RH, UK
}

(Received 29 August 1986; revised 14 November 1986)

\begin{abstract}
At least two aminoglycoside-resistance determinants from Streptomyces tenebrarius have been cloned separately in Streptomyces lividans. In each case, resistance (to kanamycin plus apramycin or to kanamycin plus gentamicin) was expressed at the level of the ribosome and involved specific methylation of $16 \mathrm{~S}$ ribosomal RNA. Hybridization and restriction analysis revealed that related genes were present in other aminoglycoside-producing actinomycetes.
\end{abstract}

\section{INTRODUCTION}

The manner in which aminoglycoside-producing actinomycetes are able to tolerate their products has received considerable attention. For example, it has been well documented that some such organisms possess aminoglycoside-modifying enzymes, most of which inactivate their substrates in vitro (for a review, see Benveniste \& Davies, 1973). Moreover, unequivocal evidence that some of these enzymes can confer resistance to aminoglycosides (at varying levels) has been obtained by cloning the relevant genes in a sensitive host, such as Streptomyces lividans (Thompson et al., 1982a; Crameri \& Davies, 1986). On the other hand, several aminoglycoside producers have been shown to possess antibiotic-resistant ribosomes, regardless of whether they also possess drug-modifying enzymes. One such strain is Streptomyces tenebrarius, producer of the nebramycin complex which includes tobramycin and other derivatives of kanamycin B plus the novel aminoglycoside, apramycin. Ribosomes from this organism were found to be highly resistant in vitro to kanamycins $\mathrm{A}, \mathrm{B}$ and $\mathrm{C}$, to the gentamicin $\mathrm{C}$ complex and also to neamine and ribostamycin (which comprise, respectively, two or three rings of the four-ring neomycin molecule), although they were somewhat more sensitive to neomycin (Yamamoto et al., 1982). Subsequently, these findings were confirmed and extended (Piendl et al., 1984). Ribosomes from $S$. tenebrarius were shown to be resistant also to apramycin and the $30 \mathrm{~S}$ sub-particle was implicated in the expression of these various effects. Furthermore, when hybrid $30 \mathrm{~S}$ ribosomal subunits (containing combinations of RNA and proteins from $S$. tenebrarius and $S$. lividans) were reconstituted in vitro and assayed in the presence of gentamicin, it was shown that some property of $16 \mathrm{~S}$ rRNA from $S$. tenebrarius was responsible for ribosomal resistance to that drug (Piendl et al., 1984).

The aim of the present work was to define the mechanism(s) responsible for all the ribosomal resistance characters of $S$. tenebrarius. Given the complexity of the resistance-profile, it was decided at the outset to clone individual aminoglycoside-resistance genes and to study the effects of their products in a sensitive background, i.e. in $S$. lividans. This work was aided by the results of other studies, then in progress, concerning ribosome-associated resistance to aminoglycosides in Micromonospora purpurea (the gentamicin producer) and in Streptomyces tenjimariensis producer of istamycin. Fragments of DNA from these two organisms had been cloned in $S$. lividans, thereby generating two populations of strains with characteristic and dissimilar resistance profiles. Both, however, possessed aminoglycoside-resistant ribosomes and, in either case, resistance was due to methylation of $16 \mathrm{~S}$ rRNA. Clones containing DNA from $M$. 
purpurea were highly resistant to kanamycin plus gentamicin (Thompson et al., 1985), whereas those possessing DNA from $S$. tenjimariensis were highly resistant to kanamycin and apramycin but were sensitive to modest levels of gentamicin (Skeggs et al., 1985). The availability of those strains for comparative purposes greatly facilitated the present analysis.

\section{METHODS}

Bacterial strains and media. The following strains were used: Streptomyces tenebrarius NCIB 11028 (nebramycin producer) and Escherichia coli MRE 600, plus several strains of Streptomyces lividans: TK 21 (a plasmid-free derivative of S. lividans 66 obtained from Professor D. A. Hopwood, John Innes Institute, Norwich, UK); TSK 1 control strain (strain TK 21 containing the high-copy-number cloning vector, pIJ702, see Katz et al., 1983); JR 14 resistant to kanamycin plus gentamicin (strain TK 21 containing pLST14; i.e. pIJ702 with $3.6 \mathrm{~kb}$ of $M$. purpurea DNA inserted into the SphI site, see Thompson et al., 1985); TSK 41 resistant to kanamycin and apramycin (strain TK 21 containing pLST 41 ; i.e. plJ 702 with $3.7 \mathrm{~kb}$ of $S$. tenjimariensis DNA inserted into the Bg/II site, see Skeggs et al., 1985); TSK 412 resistant to kanamycin and apramycin (strain TK 21 containing pLST412, i.e. pIJ702 with about $0.8 \mathrm{~kb}$ of $S$. tenjimariensis DNA inserted into the SphI site, see Skeggs et al., 1985). All Streptomyces strains were grown at $30{ }^{\circ} \mathrm{C}$ in tryptic soy broth (Difco) or on NE plates. The latter contained $1 \%(\mathrm{w} / \mathrm{v})$ glucose, $0.2 \%$ $(\mathrm{w} / \mathrm{v})$ yeast extract, $0.2 \%(\mathrm{w} / \mathrm{v})$ Casamino acids, $0.1 \%(\mathrm{w} / \mathrm{v})$ beef extract, $2 \%(\mathrm{w} / \mathrm{v})$ agar, and the $\mathrm{pH}$ was adjusted to 7.0 with $\mathrm{KOH}$ prior to autoclaving. Soft NE agar contained $0.7 \%(\mathrm{w} / \mathrm{v})$ agar.

Generation and selection of aminoglycoside-resistant clones of S. lividans. Total DNA from S. tenebrarius (prepared according to a standard procedure - Chater et al., 1982) was partially digested with Sau 3 A and the products were size-fractionated to yield 5-10 kb fragments as described previously (Skeggs et al., 1985). Of these, $5 \mu \mathrm{g}$ was mixed with $1 \mu \mathrm{g}$ of vector plasmid pIJ702 (previously linearized with $B g / \mathrm{II}$ ) and ligation was carried out using T4 DNA ligase for $1 \mathrm{~h}$ at $22{ }^{\circ} \mathrm{C}$, followed by overnight incubation at $4{ }^{\circ} \mathrm{C}$, at a final DNA concentration of $40 \mu \mathrm{g} \mathrm{ml}^{-1}$. The ligation mixture was used to transform $4 \times 10^{9}$ protoplasts from $S$. lividans TK 21, which were allowed to regenerate on ten $\mathrm{R} 2 \mathrm{YE}$ agar plates (Thompson et al., 1982b). After $20 \mathrm{~h}$ at $30^{\circ} \mathrm{C}$, the plates were overlaid with soft $\mathrm{NE}$ agar containing thiostrepton $\left(20 \mu \mathrm{g} \mathrm{ml}^{-1}\right.$ final concentration per plate) to select for transformants containing the vector plasmid. These were then replica-plated onto NE agar plates containing thiostrepton $(20 \mu \mathrm{g}$ $\mathrm{ml}^{-1}$, final concentration) plus an aminoglycoside (kanamycin, gentamicin, apramycin or neomycin at $50 \mu \mathrm{g} \mathrm{ml}^{-1}$ ).

Preparation of probes for Southern analysis. Digests of pLST 14 (with EcoRI plus BamHI) and pLST4I (with KpnI plus $B g(I I)$ were prepared as recommended by the suppliers of the restriction endonucleases and the products were separated by electrophoresis in low-melting-temperature agarose. In either case, the desired restriction fragment was the fastest-moving species in the gel, from which it was excised, denatured and annealed to mixed sequence hexadeoxynucleotides (Pharmacia). These were extended using DNA polymerase Klenow fragment (BRL) as described by Feinberg \& Vogelstein (1984) in the presence of $\left[\gamma^{-32} \mathrm{P}\right.$ ]dCTP [Amersham; $3000-4000 \mathrm{Ci} \mathrm{mmol}^{-1}$ $\left.\left(111-148 \mathrm{TBq} \mathrm{mmol}^{-1}\right)\right]$. Then, unincorporated nucleotides were removed using a column $(3 \times 0.5 \mathrm{~cm})$ of Sephadex G50 equilibrated with $3 \mathrm{~mm}-\mathrm{Tris} / \mathrm{HCl}\left(\mathrm{pH} 7.0\right.$ at $\left.20^{\circ} \mathrm{C}\right)$ containing $0.2 \mathrm{~mm}-\mathrm{Na}_{2}$ EDTA. The radiolabelled probe was eluted from the column in about $450 \mu \mathrm{l}$ of this buffer, mixed with $50 \mu \mathrm{l}$ of an aqueous solution of denatured salmon sperm DNA ( $2 \mathrm{mg} \mathrm{ml}^{-1}$, final concentration), heated for $10 \mathrm{~min}$ at $90-100^{\circ} \mathrm{C}$ and then used directly in Southern analysis, as described below.

Southern analysis. Digests of pIJ702 and its derivatives were prepared using various restriction endonucleases as follows: for pIJ702, KpnI; for pLST 14 and pLST31, EcoRI plus BamHI; for pLST41 and pLST51, KpnI plus Bg/II. The DNA fragments were separated on a $0.7 \%(\mathrm{w} / \mathrm{v})$ agarose gel (approx. $100 \mathrm{ng}$ per lane) using as running buffer

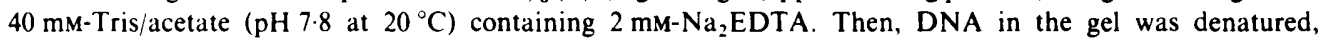
neutralized and transferred onto Genescreen Plus (New England Nuclear) by the capillary blot procedure described by the manufacturers. The DNA on the filter was then reprocessed to ensure complete denaturation before being neutralized and dried, again as recommended by the manufacturer.

Prehybridization of the filter was carried out inside a sealed bag at $42^{\circ} \mathrm{C}$ for $16 \mathrm{~h}$ with gentle agitation in $10 \mathrm{ml}$ of solution containing $50 \%(\mathrm{v} / \mathrm{v})$ deionized formamide, $1 \%(\mathrm{w} / \mathrm{v}) \mathrm{SDS}, 1 \mathrm{M}-\mathrm{NaCl}$ and $10 \%(\mathrm{w} / \mathrm{v})$ dextran sulphate. Then, $0.5 \mathrm{ml}$ of a solution (prepared as above) containing radio-labelled probe and denatured salmon sperm DNA was added to the bag and hybridization was carried out at $42^{\circ} \mathrm{C}$ for $18 \mathrm{~h}$ with gentle agitation. The filter was then washed with $2 \times 100 \mathrm{ml}$ of $2 \times \mathrm{SSC}$ (SSC is $150 \mathrm{mM}-\mathrm{NaCl}$ plus $15 \mathrm{M}$-sodium citrate) at $20^{\circ} \mathrm{C}$ for $5 \mathrm{~min}$ followed by two further washes using $2 \times \mathrm{SSC}$ plus $1 \%(\mathrm{w} / \mathrm{v}) \mathrm{SDS}$ at $55^{\circ} \mathrm{C}$ for $30 \mathrm{~min}$ and two final washes with $0.1 \times \mathrm{SSC}$ at $20^{\circ} \mathrm{C}$ for $30 \mathrm{~min}$. The filter was then dried at $20^{\circ} \mathrm{C}$ and subjected to autoradiography at $20^{\circ} \mathrm{C}$ using Fuji RX film.

Preparation of ribosomes and assays of cell-free protein synthesis. Ribosomes, ribosomal subunits and $100000 \mathrm{~g}$ post-ribosomal supernatant (S100*; so designated because it contained materials removed from ribosomes by 'high-salt' buffer containing $30 \mathrm{mM}-\mathrm{MgCl}_{2}$ plus $1 \mathrm{M}-\mathrm{NH}_{4} \mathrm{Cl}$ ) were prepared and the synthesis of polyphenylalanine directed by polyuridylic acid was followed as described previously (Skeggs et al., 1985). Regardless of the source of ribosomes or their subunits, these were always used together with $S 100^{*}$ from $S$. lividans TSK 1 (control strain). 
Methylation of 30 S ribosomal subunits. Ribosomal $30 \mathrm{~S}$ subunits from $E$. coli $(20 \mathrm{pmol})$ were incubated at $35^{\circ} \mathrm{C}$ for $1 \mathrm{~h}$ together with $5 \mu \mathrm{l}$ of $S 100^{*}$ from $S$. lividans TSK 31 or TSK 51 (as sources of methylase activity) plus $S$ adenosylmethionine as cofactor under the conditions described previously (Skeggs et al., 1985). The cofactor was omitted from control incubations. After precipitation with ethanol, 30S particles were resuspended in HRS buffer (10 mM-HEPES/KOH, pH 7.5 at $20{ }^{\circ} \mathrm{C} ; 10 \mathrm{mM}-\mathrm{MgCl}_{2} ; 50 \mathrm{mM}-\mathrm{NH}_{4} \mathrm{Cl} ; 3 \mathrm{mM}$-2-mercaptoethanol), supplemented with $E$. coli $50 \mathrm{~S}$ ribosomal subunits plus $S 100^{*}$ from $S$. lividans TSK 1 and assayed in cell free protein synthesis as above.

Antibiotics. These were obtained as follows: thiostrepton (Squibb Institute, Princeton, NJ, USA); sisomicin sulphate, (J. Davies, Pasteur Institute, Paris, France); neamine and neomycin sulphate (Upjohn Co., Kalamazoo, Mich., USA); butirosin sulphate (Warner-Lambert Co., Ann Arbor, Mich.); ribostamycin sulphate (Meiji Seika Kaisha, Ltd, Yokohama, Japan); gentamicin sulphate (Sigma).

\section{RESULTS AND DISCUSSION}

\section{Cloning and genetic analysis of resistance determinants}

Fragments of DNA from $S$. tenebrarius were cloned in $S$. lividans TK 21, using as vector the multicopy plasmid, pIJ702, and thiostrepton-resistant transformants were replica plated on kanamycin, gentamicin or apramycin (each at $50 \mu \mathrm{g} \mathrm{ml}^{-1}$ ). Several colonies were obtained on gentamicin and on apramycin although, as it happened, none grew on the plates containing kanamycin. However, all the clones selected on the former two aminoglycosides subsequently proved to be resistant to kanamycin. Two such strains, designated $S$. lividans TSK 31 and TSK 51 (originally selected on gentamicin and apramycin, respectively), were chosen for further investigation. Each contained a recombinant plasmid (pLST31, about $9 \cdot 2 \mathrm{~kb}$, and pLST51, about $9.9 \mathrm{~kb}$, respectively), that conferred the aminoglycoside resistance characteristic of strain TSK 31 or TSK 51 when retransformed into $S$. lividans TK 21 . Those patterns of collateral resistance are given in Table 1 as MIC values, together with comparable data relating to $S$. tenebrarius and the control strain, S. lividans TSK 1 (the latter being $S$. lividans TK 21 containing the vector pIJ702). Evidently, strains TSK 31 and TSK 51 were both highly resistant to kanamycin, whereas gentamicin and apramycin discriminated between them. These resistance phenotypes seemed familiar and this prompted us to compare strains TSK 31 and TSK 51 with two clones that had been generated in earlier studies. They were $S$. lividans strains JR 14 and TSK 412 which, respectively, contain DNA from the gentamicin producer $M$. purpurea and from $S$. tenjimariensis, the producer of istamycin (Thompson et al., 1985; Skeggs et al., 1985). At this stage of the investigation, it was also confirmed by Southern analysis that probes derived from the inserts in pLST31 and pLST51 each hybridized with DNA separately prepared from $S$. tenebrarius (data not given). The data in Table 1 extended the range of aminoglycosides with which strains JR 14 and TSK 412 had previously been challenged and revealed close similarities between S. lividans JR 14 and TSK 31 on the one hand and strains TSK 412 and TSK 51 on the other. Given that $S$. tenebrarius was highly resistant to each of the drugs listed in Table 1, it was

Table 1. Minimal inhibitory concentrations $\left(\mu \mathrm{g} \mathrm{ml}^{-1}\right.$ ) of aminoglycoside antibiotics for S. lividans strains and for $S$. tenebrarius

Spores were streaked on NE agar plates (see Methods) containing antibiotics and growth was monitored after $3-5 \mathrm{~d}$ incubation at $30^{\circ} \mathrm{C}$.

S. lividans strain

\begin{tabular}{lcccccc}
\cline { 2 - 4 } & TSK 1(control) & JR 14 & TSK 31 & TSK 51 & TSK 412 & S. tenebrarius \\
Kanamycin & $10-30$ & $>1000$ & $>1000$ & $>1000$ & $>1000$ & $>1000$ \\
Tobramycin & $3-10$ & $300-1000$ & $300-1000$ & $100-300$ & $100-300$ & $>1000$ \\
Apramycin & $<1$ & $<1$ & $1-3$ & $300-1000$ & $300-1000$ & $>1000$ \\
Gentamicin & $3-10$ & $>1000$ & $>1000$ & $10-30$ & $10-30$ & $>1000$ \\
Sisomicin & $3-10$ & $>1000$ & $>1000$ & $100-300$ & $100-300$ & $>1000$ \\
Neamine & $10-30$ & $10-30$ & $10-30$ & $>1000$ & $>1000$ & $>1000$ \\
Ribostamycin & $3-10$ & $3-10$ & $3-10$ & $>1000$ & $>1000$ & $>1000$ \\
Butirosin & $<1$ & $<1$ & $<1$ & $>1000$ & $>1000$ & $>1000$ \\
Neomycin & $1-3$ & $3-10$ & $3-10$ & $30-100$ & $30-100$ & $>1000$
\end{tabular}



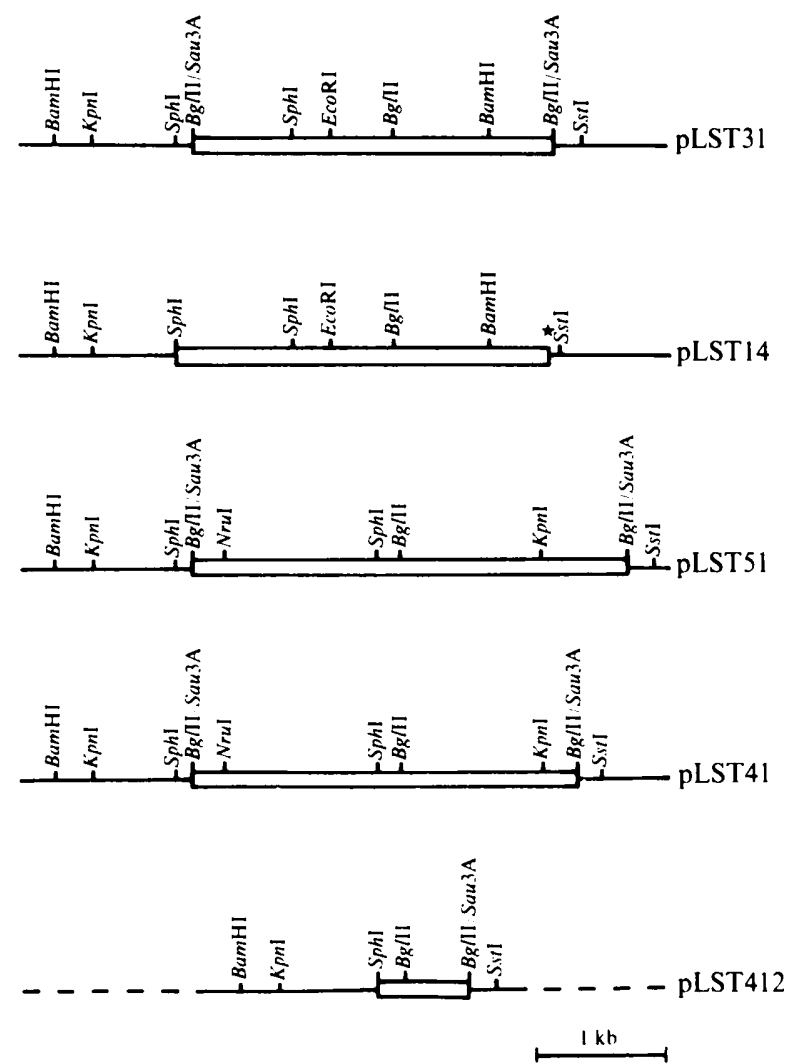

Fig. 1. Restriction maps of DNA fragments carrying aminoglycoside-resistance genes. Aminoglycoside-resistance genes were cloned using pIJ702 as vector. Boxes represent inserted DNA from the following organisms: in pLST31 and pLST51, S. tenebrarius; in pLST14, M. purpurea; in pLST41 and pLST412, S. tenjimariensis. In pLST 14, $\star$ indicates loss of the SphI cloning site. The whole of the kanamycin-apramycin resistance gene from $S$. tenjimariensis is contained within pLST412 (insert size $0.8 \mathrm{~kb}$ ) and has been subcloned from pLST41 (Skeggs et al., 1985). The kanamycin-gentamicin resistance gene from $M$. purpurea has been located within pLST14 by subcloning (D. J. Holmes, unpublished data). It is contained within about $1 \cdot 1 \mathrm{~kb}$ of the inserted DNA that begins between the $B a m H I$ and $B g / I I$ sites and extends leftwards to a point between the EcoRI site and the proximal SphI site.

interesting that fairly high levels of resistance to most of those compounds were also displayed by $S$. lividans TSK 31 or by strain TSK 51 or by both. On the other hand, strain TSK 31 was only marginally resistant to neomycin and, although the resistance level of strain TSK 51 was significantly higher, it did not approach that seen with $S$. tenebrarius. Accordingly, repeated attempts were made, using $S$. tenebrarius DNA, to generate clones that would grow on higher concentrations of neomycin (e.g. $50 \mu \mathrm{g} \mathrm{ml}^{-1}$ ), but to no avail.

When the DNA fragments from $S$. tenebrarius cloned in pLST31 and pLST51 had been subjected to restriction analysis (Fig. 1), they were compared with previously unpublished maps of the $M$. purpurea DNA fragment present in pLST14 (isolated from $S$. lividans JR 14) and the $S$. tenjimariensis DNA contained in pLST41. The latter DNA fragment (about $3.7 \mathrm{~kb}$ ) contained the kanamycin-apramycin resistance gene, which was subsequently isolated on pLST412 as a smaller insert $(0.8 \mathrm{~kb}$ in length). The similarities between the inserts in pLST31 compared with pLST14 and in pLST51 compared with pLST41 were obvious, suggesting that the similar patterns of aminoglycoside resistance linking S. lividans strain JR 14 with TSK 31 and strain TSK 412 with TSK 51 resulted from their possession of related (and possibly homologous) resistance genes. Further evidence in support of this idea was obtained when a fragment of $M$. 


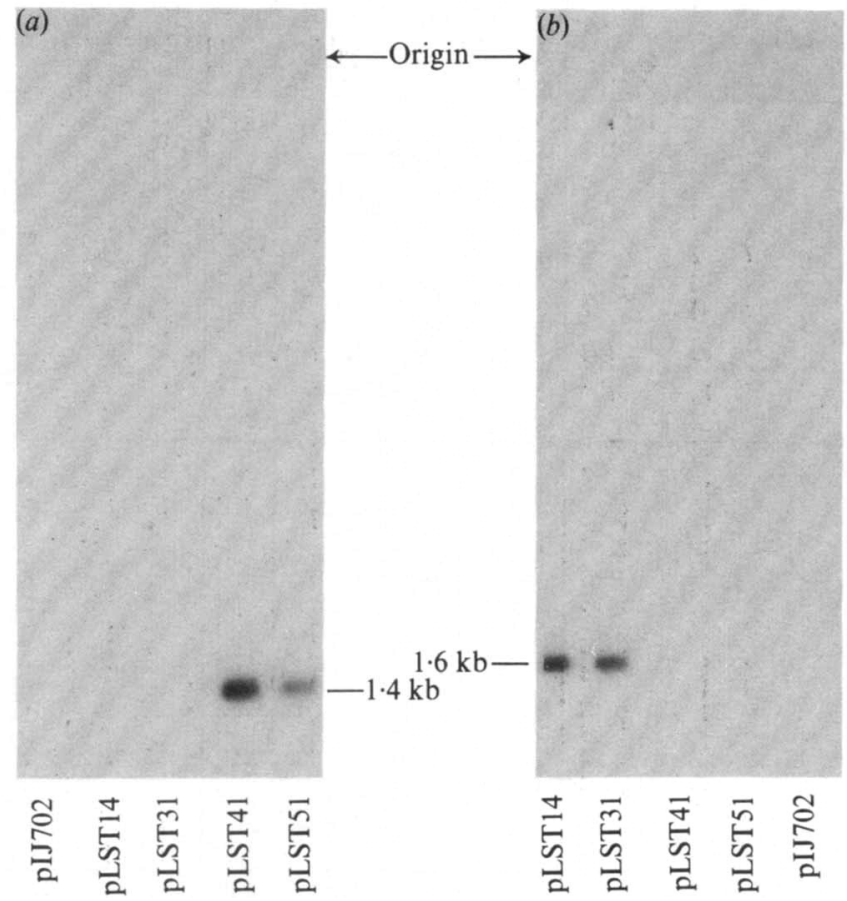

Fig. 2. Southern analysis of aminoglycoside-resistance genes from various actinomycetes. Radiolabelled probes were prepared using $(a)$ the $B g / I I-K p n I$ fragment from the insert in pLST 41 and $(b)$ the EcoRI - BamHI fragment from the insert in pLST14 (see Fig. 1). These probes contained (a) at least $75 \%$ of the kanamycin-apramycin resistance gene from $S$. tenjimariensis, plus adjacent DNA, and $(b)$ at least $55 \%$ of the kanamycin-gentamicin resistance gene from $M$. purpurea, again plus adjacent DNA from that organism. Hybridization was carried out with filters containing linearized pIJ702 plus the recombinant plasmids pLST14, pLST3I, pLST4I and pLST51, each of which had been cleaved into three restriction fragments as follows: $5.0 \mathrm{~kb}, 2.5 \mathrm{~kb}$ and $1.6 \mathrm{~kb}$ from pLST $14 ; 5.1 \mathrm{~kb}, 2.5 \mathrm{~kb}$ and $1.6 \mathrm{~kb}$ from pLST31; $5.0 \mathrm{~kb}, 3.0 \mathrm{~kb}$ and $1.4 \mathrm{~kb}$ from pLST41; $5.5 \mathrm{~kb}, 3.0 \mathrm{~kb}$ and $1.4 \mathrm{~kb}$ from pLST51 (for further details see Methods and Fig. 1).

purpurea DNA, isolated from pLST14 and known to contain most of the kanamycin-gentamicin resistance determinant (see legend to Fig. 1), was used to probe Southern blots containing restriction fragments from pIJ702, pLST41, pLST31, pLST51 and pLST14. Hybridization at high stringency was observed with the piece of $S$. tenebrarius DNA present in pLST31 but not with any part of pLST41, pLST51 or pIJ702 (Fig. 2). Conversely, when a similar Southern blot was probed with a radiolabelled restriction fragment derived from pLST41 and containing most of the kanamycin-apramycin resistance determinant (see legend to Fig. 1), hybridization at high stringency was observed with the $S$. tenebrarius DNA insert in pLST51 but not with any part of pLST31. These obvious similarities between the resistance genes from $S$. tenebrarius and those isolated from $M$. purpurea and $S$. tenjimariensis influenced our approach to the biochemical characterization of the mechanisms of aminoglycoside resistance in strains TSK 31 and TSK 51, as described below. Before that, however, another aspect of the homologies evident in Fig. 1 deserves further comment. The pieces of DNA being compared, between pLST14 and pLST31 on the one hand and between pLST41 and pLST51 on the other, appeared similar over much more than gene-sized contours, at least at this crude level of analysis. In the absence of additional data, the significance of these 'extra' homologies cannot be assessed and they may well be trivial. Nevertheless, it might be instructive to know whether resistance determinants in these various aminoglycoside-producing organisms are physically adjacent to other common genes involved in aminoglycoside metabolism (more of this, later). 


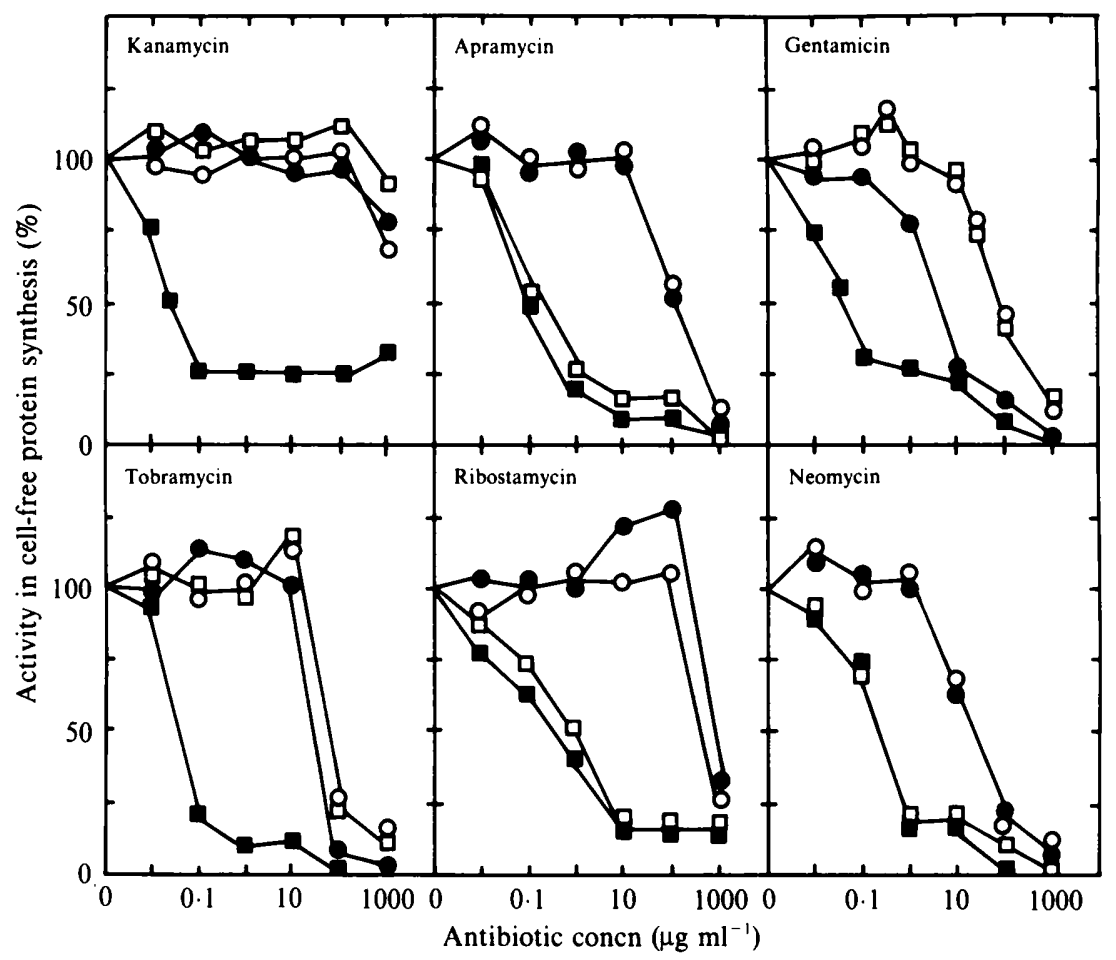

Fig. 3. Effects of aminoglycosides on cell-free protein synthesis. Assays contained S100* from $S$. lividans TSK 1 (control strain) together with 5 pmol 70 S ribosomes from S. lividans TSK 31 ( $\square$ ) (100\% activity $=25$ Phe per ribosome $\left.\mathrm{h}^{-1}\right) ; S$. lividans TSK $51(\mathrm{O})\left(100 \%\right.$ activity $=20$ Phe per ribosome $\left.\mathrm{h}^{-1}\right)$; S. tenebrarius $(O)\left(100 \%\right.$ activity $=15$ Phe per ribosome $\left.\mathrm{h}^{-1}\right) ; S$. lividans $\mathrm{TSK} 1(\square)(100 \%$ activity $=$ 15 Phe per ribosome $\left.\mathrm{h}^{-1}\right)$. Activities are given as pmol phenylalanine incorporated per pmol ribosomes per hour (Phe per ribosome $\mathrm{h}^{-1}$ ). Antibiotic concentrations have been corrected to account for sulphate and refer to free base.

\section{Biochemical analysis of resistance mechanisms}

Prior to the present work, it had already been shown that ribosomes from $S$. tenebrarius were resistant in vitro to a range of aminoglycosides, including kanamycin, gentamicin, apramycin and, to a lesser extent, neomycin (Yamamoto et al., 1982; Piendl et al., 1984). Those results were amply confirmed here (and extended) when ribosomes from $S$. lividans strains TSK 31 and TSK 51 were compared with those from $S$. lividans TSK 1 and $S$. tenebrarius (negative and positive controls, respectively) in their response to aminoglycosides in vitro. In these experiments, ribosomes from the various organisms were supplemented with $\mathrm{S} 100^{*}$ from strain TSK 1 and assayed in protein-synthesizing systems directed by polyuridylic acid. Some of the results are shown in Fig. 3. Ribosomes from S. lividans TSK 31 were resistant to kanamycin, tobramycin and gentamicin, whereas those from strain TSK 51 were highly resistant to kanamycin, apramycin and ribostamycin but showed only low-level resistance to gentamicin and neomycin. Also, in other studies (data not presented), ribosomes from $S$. lividans TSK 51 and from $S$. tenebrarius proved to be highly resistant in vitro to neamine and to butirosin. Two general conclusions were drawn from these data. First, for each $S$. lividans strain, the profile of ribosomal resistance observed in vitro reflected the phenotype of the intact organism. Secondly, the levels of resistance to individual aminoglycosides displayed by $S$. tenebrarius ribosomes were matched by the responses of ribosomes from $S$. lividans TSK 31 and/or strain TSK 51. Thus, it was concluded that the fragments of $S$. tenebrarius DNA that had been cloned in strains TSK 31 and TSK 51 probably contained all the aminoglycoside-resistance determinants that affected the ribosome. It was also evident that the patterns and levels of resistance to aminoglycosides 


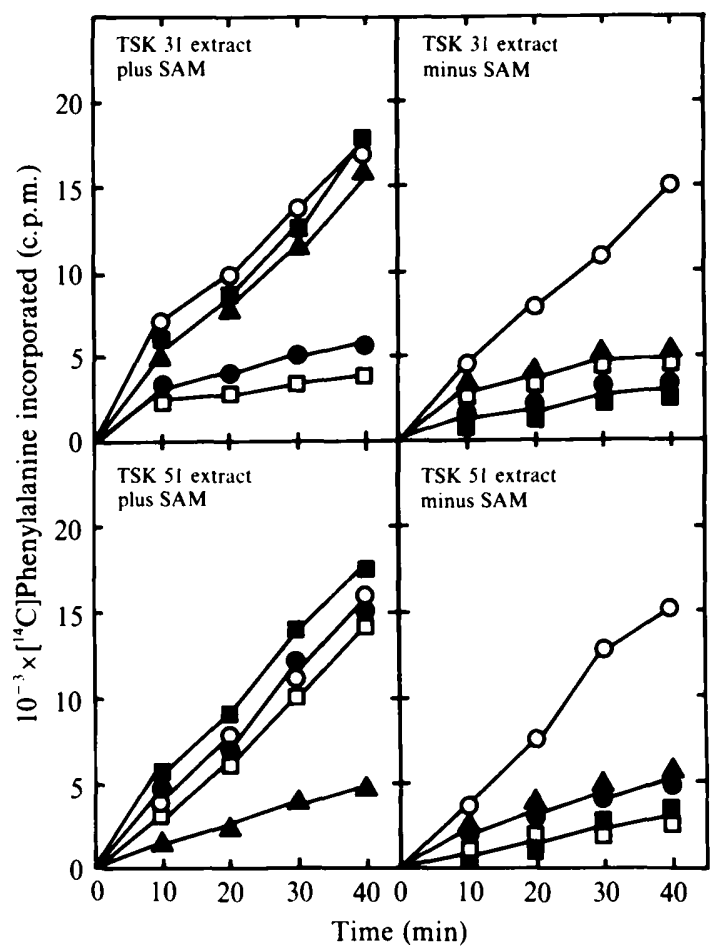

Fig. 4. Correlation between methylation of $30 \mathrm{~S}$ ribosomal subunits and resistance to aminoglycosides. Ribosomal $30 \mathrm{~S}$ subunits (5 pmol) from $E$. coli were preincubated with $\mathrm{S} 100^{*}$ (as a source of methylase activity) either from $S$. lividans TSK 31 or $S$. lividans TSK 51 in the presence or absence of $S$ adenosylmethionine (SAM). After ethanol precipitation, the particles were supplemented with $E$. coli $50 S$ ribosomal subunits $(5 \mathrm{pmol})$ and $S 100^{*}$ from $S$. lividans TSK 1 and assayed in cell-free protein synthesis in the absence of drugs $(O)$ or in the presence of tobramycin $(\square)$, apramycin $(\square)$, ribostamycin (O) or gentamicin $(\Lambda)$, each at $10 \mu \mathrm{g} \mathrm{ml}^{-1}$ final concentration of free base.

observed with ribosomes from strains TSK 51 and TSK 31 were indistinguishable from those seen previously with ribosomes from $S$. lividans TSK 412 and JR 14 respectively (Skeggs et al., 1985; Thompson et al., 1985). Again, these results were compatible with the idea that $S$. tenebrarius contains resistance genes that are homologous with those from $S$. tenjimariensis and $M$. purpurea that had been cloned previously. That being so, the likely resistance mechanisms operating in S. lividans TSK 31 and TSK 51 were evident, since it had already been shown that ribosomal resistance to aminoglycosides in S. lividans JR 14 and in strain TSK 412 was due to methylation of 16S RNA. Accordingly, this point was addressed directly.

Using $S 100^{*}$ preparations from $S$. lividans TSK 31 and TSK 51 , as sources of putative methylase activity, and $S$-adenosyl $\left[\right.$ methyl $\left.{ }^{-3} \mathrm{H}\right]$ methionine as cofactor, the incorporation of radiolabelled methyl groups into $E$. coli $30 \mathrm{~S}$ ribosomal subunits was followed. In controls, $\mathrm{S} 100^{*}$ from $S$. lividans TSK 1 was used to indicate the 'background' level of incorporation due to other rRNA methylases, present in $S$. lividans but not in $E$. coli. The results were unequivocal. Substantially higher levels of incorporation (amounting to about 0.6 methyl groups per $30 \mathrm{~S}$ particle) were observed with $\mathrm{S} 100^{*}$ extracts from the clones compared with the control strain and in each case it was $16 \mathrm{~S}$ rRNA that was methylated (data not shown). Then, to confirm that methylation caused ribosomal resistance, the experiment was repeated using unlabelled $S$ adenosylmethionine. After incubation with $S 100^{*}$, plus or minus $S$-adenosylmethionine, the $30 \mathrm{~S}$ ribosomal subunits were assayed for their response to aminoglycosides in a protein-synthesizing system. To do this, they were supplemented with $50 \mathrm{~S}$ ribosomal subunits from $E$. coli plus $\mathrm{S} 100^{*}$ (source of protein synthesis factors, etc.) from S. lividans TSK 1. The results are shown in Fig. 4. 
Resistance to specific aminoglycosides was observed only when $30 \mathrm{~S}$ particles had been incubated with $S$-adenosylmethionine in addition to $S 100^{*}$ from either of the clones. Moreover, the resistance profiles resembled those of native ribosomes from strains TSK 31 and TSK 51. These results proved that specific methylation of $16 \mathrm{~S}$ RNA by the products of $S$. tenebrarius genes could render $E$. coli ribosomes resistant to aminoglycosides. Presumably, similar mechanisms also operate in $S$. tenebrarius; hence we conclude that ribosomes from that organism owe their complex pattern of aminoglycoside resistance to methylation at (at least two) specific sites within 16S RNA.

\section{Conclusions}

Although all the resistance characteristics of $S$. tenebrarius ribosomes can be adequately accounted for in terms of 16S RNA methylation, this is still not sufficient to account for the phenotype of that strain - even relating to antibiotics against which ribosomal resistance is expressed. Thus, in vitro, ribosomes from $S$. tenebrarius were indistinguishable from those of $S$. lividans TSK 31 and TSK 51 in their response to tobramycin, yet the MIC values were different for the three strains. Indeed, the data in Table 1 suggest that some other tobramycin-resistance determinant from $S$. tenebrarius might have been cloned in $S$. lividans TSK 31. Again, $S$. tenebrarius ribosomes were similar to those from $S$. lividans TSK 51 in their response to apramycin or neomycin but the intact organisms displayed different levels of resistance. We have no data to account for these observations but we note that, in common with other aminoglycoside producers, $S$. tenebrarius possesses aminoglycoside-modifying activity (Davies, 1980; Yamamoto et al., 1982). Conceivably, this could contribute to the phenotype as could the permeability properties of the mycelial surface of $S$. tenebrarius. Data bearing upon these points are currently unavailable.

Finally, on a teleological note, it is intriguing to enquire why $S$. tenebrarius carries the seemingly redundant rRNA methylase gene(s) that we have cloned in S. lividans TSK 31. Possibly, $S$. tenebrarius requires that DNA for protection against some other antibiotic product as yet uncharacterized. Alternatively, it could be that the presence of the 'extra' resistance determinant(s) reflects a recurrent pattern in the genetic organization of antibiotic-producing organisms. Thus, in $S$. tenebrarius, genes involved in the production of apramycin and tobramycin might form separate clusters, each associated with a methylase gene. Such physical linkage between antibiotic biosynthetic genes and resistance determinants has already been observed in several contexts (for a review, see Hopwood et al., 1986). Whether it occurs in $S$. tenebrarius and, if so, whether on the chromosome or on a plasmid (or on both) remains to be established.

This work was funded by the Medical Research Council.

\section{REFERENCES}

Benveniste, R. \& Davies, J. (1973). Aminoglycoside antibiotic-inactivating enzymes in actinomycetes similar to those present in clinical isolates of antibiotic-resistance bacteria. Proceedings of the National Academy of Sciences of the United States of America 70, 2276-2280.

Chater, K. F., Hopwood, D. A., Kieser, T. \& Thompson, C. J. (1982). Gene cloning in Streptomyces. Current Topics in Microbiology and Immunology 96, 69-95.

Crameri, R. \& Davies, J. E. (1986). Increased production of aminoglycosides associated with amplified antibiotic resistance genes. Journal of Antibiotics 39, 128-135.

DAviEs, J. (1980). Enzymes modifying aminocyclitol antibiotics and their roles in resistance determination and biosynthesis. In Aminocyclitol Antibiotics, pp. 323-334. Edited by K. L. Rinehart, Jr \& T. Sumai. Washington, DC: American Chemical Society.

Feinberg, A. P. \& Vogelstein, B. (1984). A technique for radiolabelling DNA restriction endonuclease fragments to high specific activity. Analytical Biochemistry 137, 266-267.

Hopwood, D. A., BibB, M. J., Chater, K. F., Janssen, G. R., Malpartida, F. \& Smith, C. P. (1986). Regulation of gene expression in antibiotic-producing Streptomyces. Symposia of the Society for General Microbiology 39, 251-276.

KATZ, E., ThOMPSON, C. J. \& Hopwood, D. A. (1983). Cloning and expression of the tyrosinase gene from Streptomyces antibioticus in Streptomyces lividans. Journal of General Microbiology 129, 2703-2714.

Piendl, W., Böck, A. \& Cundliffe, E. (1984). 
Involvement of $16 \mathrm{~S}$ ribosomal RNA in resistance of the aminoglycoside-producers Streptomyces tenjimariensis, Streptomyces tenebrarius and Micromonospora purpurea. Molecular and General Genetics 197, 24-29.

Skeggs, P. A., Thompson, J. \& Cundliffe, E. (1985). Methylation of $16 \mathrm{~S}$ ribosomal RNA and resistance to aminoglycoside antibiotics in clones of Streptomyces lividans carrying DNA from Streptomyces tenjimariensis. Molecular and General Genetics 200, 415-421.

Thompson, C. J., SKinner, R. H., Thompson, J., Ward, J. M., Hopwood, D. A. \& Cundliffe, E. (1982a). Biochemical characterization of resistance determinants cloned from antibiotic-producing streptomycetes. Journal of Bacteriology 151, 678-685.
Thompson, C. J., WARD, J. M. \& Hopwood, D. A. $(1982 b)$. Cloning of antibiotic resistance and nutritional genes in streptomycetes. Journal of Bacteriology 151, 668-677.

Thompson, J., Skeggs, P. A. \& Cundliffe, E. (1985). Methylation of $16 \mathrm{~S}$ ribosomal RNA and resistance to the aminoglycoside antibiotics gentamicin and kanamycin determined by DNA from the gentamicin producer, Micromonospora purpurea. Molecular and General Genetics 201, 168-173.

Yamamoto, H., Нotta, K., OKami, Y. \& Umezawa, H. (1982). Mechanism of resistance to aminoglycoside antibiotics in nebramycin-producing Streptomyces tenebrarius. Journal of Antibiotics 35, 1020 1025. 